\title{
The Effect of Knowledge and Attitude on Fall Prevention Activities among Nursing Staff in Long-Term Care Hospitals
}

\author{
Yeong Hwa Han ${ }^{1}$, Hye Young Kim² ${ }^{*}$, Hye Sun Hong² \\ ${ }^{1}$ Graduate School, Keimyung University, Daegu, South Korea \\ ${ }^{2}$ Department of Nursing, Keimyung University, Daegu, South Korea \\ Email: ^hye11533@kmu.ac.kr
}

How to cite this paper: Han, Y.H., Kim, H.Y. and Hong, H.S. (2020) The Effect of Knowledge and Attitude on Fall Prevention Activities among Nursing Staff in Long-Term Care Hospitals. Open Journal of Nursing, 10, 676-692.

https://doi.org/10.4236/ojn.2020.107048

Received: June 9, 2020

Accepted: July 12, 2020

Published: July 15, 2020

Copyright () 2020 by author(s) and Scientific Research Publishing Inc. This work is licensed under the Creative Commons Attribution International License (CC BY 4.0).

http://creativecommons.org/licenses/by/4.0/

\begin{abstract}
Background: The fall prevention activities of nursing staff are emphasized more in order to reduce the incidence of falls in elderly people in long-term care hospitals. Objectives: To examine the extent of knowledge and attitude about falls and the degree of fall prevention activities among nursing staff in long-term care hospitals, and to identify the effect of knowledge and attitude about falls on prevention activities. Design: The data collection was, in the period between July 10th, 2017 and August 10th, 2017, accumulated by constructive questionnaires targeting 138 nurses and nurse aids who are employed within five long-term care hospitals. Methods: The statistical processing was as follows: the frequency, percentage, mean and standard deviation, independent t-test, one-way ANOVA, Pearson's correlation coefficients, and hierarchical regression analysis. Results: The fall prevention activities showed a significant difference statistically in the fields of age $(F=5.33, p=0.002)$, working career $(\mathrm{F}=3.98, \mathrm{p}=0.014)$, positions $(\mathrm{t}=2.71, \mathrm{p}=0.008)$, subject's experience with patient falls $(\mathrm{t}=2.15, \mathrm{p}=0.033)$, fall prevention education ( $\mathrm{t}$ $=3.32, p=0.001)$. As for the correlation between knowledge and attitude towards falls and fall prevention activities, knowledge and attitude towards fall $(\mathrm{r}=0.45, \mathrm{p}<0.001)$, knowledge and fall prevention activities $(\mathrm{r}=0.27, \mathrm{p}<$ $0.002)$, attitude towards falls and fall prevention activities $(r=0.42, p<0.001)$ had significantly positive correlations. As for the fall prevention activities of nursing staff in long-term care hospitals, their attitude towards falls $(\beta=0.32$, $\mathrm{p}<0.001)$ had an effect on fall prevention activities. Conclusion: In order to increase fall prevention activities in long-term care hospitals, nursing staff attitude towards falls is important. Therefore, we need to explore diverse strategies to promote fall prevention activities of nursing.
\end{abstract}




\section{Keywords}

Knowledge, Attitude, Nursing, Long-Term Care

\section{Introduction}

According to the elderly population census in Korea, the population aged 65 or over in 2018 (13.4\%) is expected to become aging at $20.8 \%$ in 2026 entering the elderly society [1]. In the line with this rapid increase in the elderly population, the elderly's care has emerged as a social issue due to weakening respect for the elderly, nuclear family, and women's social advancement [2]. As a way to solve these problems since the 1990s, the number of elderly nursing facilities increased and long-term care hospitals began to develop. One hundred fifteen long-term care hospitals in 2004 increased to 867 in 2010, and up to 11.9 times in 2016 (1372). The number of inpatient beds is $30.4 \%$ of all medical facilities, and the number of hospitalized patients is approximately 320,000 [3]. In modern society, the increasing number of aging population and institutionalized persons leads to major public health problems. One American article reported that about 30\% to $50 \%$ of the population in the nursing homes experienced falls, with approximately 1.5 falls per nursing home bed per year [4].

When a fall occurs in an inpatient elderly person, the first responder is likely to be an employee in the vicinity of the patient [5]. In particular, nursing-related workers in long-term care hospitals support daily life, such as meals and bathing assistance, mobility and position change of hospitalized seniors, and are in charge of maintaining and promoting physical functions and managing the environment [6]. It is likely that they are at the front to manage when the residents of the nursing home experience the falls.

Examining the current status of nursing care workers in long-term care hospitals, the number of nursing personnel per bed in those hospitals increased after the nursing grading system was implemented, but the ratio of nurses in the nursing workplace was increased significantly in the statistical data with $4.7 \%$ in 2007 and 18.0\% in 2010 [7]. Despite the fact that nurses are the core personnel of long-term care hospitals, the Ministry of Health, Welfare and Family Affairs has recognized nursing assistants as nursing support personnel in long-term care hospitals since 2008 due to difficulties in recruiting nurses. Due to the inclusion of nursing assistants into the nursing grade system and the difficulty of hiring nurses, a number of long-term care hospitals actively hire nursing assistants rather than nurses [7]. Therefore, the fall prevention activities of nursing workers, including nursing assistants, are emphasized more in order to reduce the incidence of falls in elderly people in long-term care hospitals.

Patient risks for falls are described as both intrinsic and extrinsic. Intrinsic factors are patient related factors such as age, comorbidity, previous falls, gait, visual/auditory impairment, musculoskeletal deficits and cognitive impairment, 
whereas, extrinsic factors are related to the physical environment of the hospital, medications, supportive and assistive equipment in bathrooms, lighting, and footwear [8]. Medications, such as opioids, neuroleptic agents, benzodiazepines and tricyclic antidepressants, were identified as extrinsic factors leading to increased fall risk [9]. It is recommended, therefore, that all hospitalized patients over the age of 65 years (and those over 54 years judged to have specific risks) should have a multifactorial fall risk assessment. Identifying risks and providing effective interventions where possible can reduce falls by $20 \%-30 \%$ [10]. In addition, for fall prevention activities, it is important to form an interest in falls and an attitude to participate in fall prevention activities [11]. According to the study of Spiva et al. [12], creating a safety culture within the organization is the first step for implementation. Agency for Healthcare Research and Quality (AHRQ) explained the culture of safety as "the attitudes and behaviors that are related to patient safety and that are expected to be appropriate to promote patient safety" [13].

Rogers' Diffusion of Innovation Theory [14] presents us a five-step decision innovation process by which we can stimulate change into an intervention called safety culture: knowledge, persuasion, decision, implementation, and confirmation. Therefore, a high attitude toward falling means that there is a lot of interest in falling, which means that it has a positive effect on fall prevention activities [15]. Therefore, the knowledge and attitude of fall can be a major factor influencing fall prevention activities. In reviewing previous studies conducted in Korea, the majority of studies about the knowledge, attitudes, and preventive activities of fall are conducted for hospitalized elderly patients [16] [17], and for general hospital nurses [17] [18] [19]. The study of falls for nursing employees was performed in elderly nursing facilities [20] [21].

However, it is insufficient that the research examined the knowledge, attitudes, and preventive activities of falls in nursing workers for the elderly with high risk of falls and long-term hospital stays at long-term care hospitals. Therefore, this study examined the degree of knowledge, attitude and prevention activities of nursing care workers who care for elderly patients directly to prevent falls in long term care hospitals. The study also confirmed the effect of the knowledge and attitude about falls on the preventive activities in the nursing employees. The results of this study will help design more effective strategies to prevent falls of the elderly. The specific purpose objectives for this study is are as follows.

- Identify the participant's knowledge, attitude and fall prevention activities.

- Identify differences in knowledge, attitudes, and falls prevention activities according to the general characteristics and fall-related characteristics of the subjects.

- Identify the correlation between the subject's knowledge and attitude of fall, and fall prevention activities.

- Identify the impact of the subject's knowledge and attitude on fall prevention 
activities.

\section{Materials and Methods}

\subsection{Design}

This study is a descriptive research study to identify the degree of nurse's knowledge, attitudes and fall prevention activities toward falls and the effects of falls knowledge and attitudes on fall prevention activities for nursing care workers in long-term care hospitals.

\subsection{Participants}

The subjects of this study were 138 nursing staff that consisted of nurses and nursing assistants working in five long-term care hospitals located in cities A and B. The subjects were selected if they understood the purpose and contents of this study and agreed in writing to participate in the study. The number of subjects was calculated using the $G^{\star}$ Power 3.1.9 program. In multiple regression analysis, when the significance level was 0.05 , the median effect size was 0.15 , the power was 0.80 , and 13 predictors (11 general characteristics, knowledge and attitude about falls), 131 samples were calculated.

\subsection{Measurements}

This research tool used a structured questionnaire. The contents of the questionnaire consisted of 51 items, consisting of 11 items of general characteristics and fall-related characteristics, 14 items of knowledge about falls, 13 items of attitudes on falls, and 13 items of preventive actions against falls (see Appendix 1).

\subsubsection{General Characteristics and Fall-Related Characteristics}

The general characteristics of the study subjects consisted of gender, age, number of years of clinical work, number of years of work in a nursing hospital, type of work, and final education in 6 questions. The fall-related characteristics consisted of five questions, fall experience and number of falls of the patient in charge, the number and frequency of falls prevention training, the type of fall education, the time of fall education, and the number of falls prevention education.

\subsubsection{Fall Knowledge}

This study used the tools for measuring your fall knowledge which was developed by Kim [17] and modified and supplemented by Lee [22]. This tool consisted of 14 questions, and "Yes" was treated as 1 point for the correct answer, and 0 points as "No" and "I don't know" as the incorrect answer. In addition, the 5th, 8th, 10th, 12th, and 13th were treated as reverse questions. The total score is from a minimum of 0 to a maximum of 14 , and the higher the score, the higher the knowledge of fall. Reliability Cronbach's $\alpha$ in the study of Kim [17] was 0.76, Cronbach's $\alpha$ in the study of Lee [22] was 0.76 , and the reliability KR-20 was 0.68 . 


\subsubsection{Attitude to Fall}

In this study, the tools developed by Kim [17] were used to measure attitudes toward falls. The tool consists of 13 questions. Measured on the Likert scale of "Not at all" 1 point, "No" 2 points, "Normal" 3 points, "Yes" 4 points, "Very Yes" 5 points, question 2, 8, 9, 11, and 12 were processed as reverse questions. The score ranges from a minimum of 13 to a maximum of 65 . The higher the score, the higher the interest in falls and its care. In the study of Kim [17], the reliability Cronbach's $\alpha$ was 0.75 , and in this study, Cronbach's $\alpha$ was 0.72 .

\subsubsection{Fall Prevention Activities}

In this study, to measure the extent of fall prevention activities, the questions developed by Kim [16] for elderly patients in hospital were modified and supplemented by Kim [15] for nurses at senior hospitals. The tool consists of a total of 13 questions which relate to preventive actions against falls that may occur in the hospital. It was measured on a 5-point Likert scale of 5 points for "very good", 4 points for "yes", 3 points for "normal", 2 points for "not really", and 1 point for "not very" ranging from the minimum score 13 to the maximum of 65 , and the higher the score, the higher the degree of practice of fall prevention activities. In the study of Kim [16], the reliability Cronbach's $\alpha$ was 0.68 , in the study of Kim [15], the Cronbach's $\alpha$ was 0.90, and in this study, the Cronbach's $\alpha$ was 0.94 .

\subsection{Data Collection}

Data collection for this study was conducted from July 10, 2017 to August 10, 2017 for nurses and nursing assistants working in five nursing homes located in cities $\mathrm{A}$ and $\mathrm{B}$. The researcher decided the interview time by phone with the department head of the hospital before collecting the data, and then the researcher visited the hospital directly and explained the purpose and intent of the study to the head of the nursing department and received approval for the data collection. Subsequently, the researcher explained the purpose and contents of the study to the subjects, and then distributed the questionnaire to the subjects who agreed in writing to understand and participate in the research. The questionnaire was made by the subjects themselves, and the completed questionnaire was collected by the researcher. A total of 145 copies of the questionnaire were distributed, and 144 copies were collected, and 138 copies of the questionnaire except for the six questionnaires with unsuccessful responses were used for the final analysis.

\subsection{Ethics}

The researcher conducted data collection after being approved of the data collection after deliberation by the International Review Board (IRB) of K University in consideration of the ethical issues of the subjects for participation in the research (40525-201706-HR-34-02). Before collecting the data, the subjects were informed of the purpose of the study, the duration of the survey, the benefits and 
risks of participating in the study, and confidentiality of personal information. The researchers also explained to the participants that the questionnaire was used for research purposes only, and the voluntariness and anonymity of the study participants were guaranteed. In addition, the subject could stop at any time if they were reluctant to participate in the study, and there was no disadvantage in the case. After the explanation of participation in research, the participants were given small thank-you gifts.

\subsection{Data Analysis}

The data collected in this study were analyzed using the SPSS / WIN 22.0 program, and the specific analysis method is as follows.

- The general characteristics of the subjects were analyzed by frequency, percentage, mean and standard deviation.

- The subject's knowledge, attitude and fall prevention activity were analyzed by means and standard deviation.

- Differences in knowledge, attitudes, and preventive activities of falls according to the general characteristics of the subjects were analyzed by independent sample t-test and one-way ANOVA, and post-test verification was verified by Scheffé test.

- The correlation between the subject's knowledge and attitude of falls and fall prevention activities was verified by Pearson's correlation coefficients.

- In order to identify the effect of the subject's knowledge and attitude on fall prevention activities, it was verified by hierarchical regression analysis.

\section{Results}

The subjects for this study were 138 nursing staff, 136 (98.6\%) were female, 57 (41.3\%) were aged 50 to 59 and the average was $47.64 \pm 8.82$ years old. In addition, 59 subjects $(42.8 \%)$ had the clinical career experience of one to nine years or less. Eighty eight subjects (63.8 percent) experienced falls in patients, and 34 (38.6 percent) experienced more than three times. In the past year, 118 subjects (85.5 percent) had fall prevention education.

\subsection{Fall Prevention Activities by the General Characteristics}

Examining the preventive activities for falls according to general characteristics, there was a significant difference among the age of the subjects $(\mathrm{F}=5.33, \mathrm{p}=$ $0.002)$, clinical work experience $(F=3.98, p=0.014)$, and the type of occupation engaged $(t=2.71, p=0.008)$. There was a significant difference. In the subject's age, those below 40 years old engaged in lower fall prevention activity than those aged 40 to 49 years old $(p=0.022)$, those aged 50 to 59 years old $(p=0.044)$, and over 60 years old $(\mathrm{p}=0.006)$. The subjects with more than 20 years of clinical work experience also were statistically significantly involved in preventive activities higher than that of 1 year or more and less than 10 years $(p=0.036)$. In the industry, nurses showed significantly higher fall prevention activities than nursing assistants (Table 1). 
Table 1. Fall prevention activities by the general characteristics $(\mathrm{N}=138)$.

\begin{tabular}{|c|c|c|c|c|c|}
\hline \multirow{2}{*}{ Characteristics } & \multirow{2}{*}{ Categories } & \multirow{2}{*}{ N (\%) } & \multicolumn{3}{|c|}{ Prevention activity } \\
\hline & & & $\mathrm{M} \pm \mathrm{SD}$ & $\mathrm{t} / \mathrm{F}$ & $\mathrm{p}$ \\
\hline \multirow{2}{*}{ Gender } & Male & $2(1.4)$ & $53.50 \pm 3.54$ & -0.61 & 0.545 \\
\hline & Female & $136(98.6)$ & $56.18 \pm 6.20$ & & \\
\hline \multirow{4}{*}{ Age (years) } & $<40^{\mathrm{a}}$ & $25(18.1)$ & $52.32 \pm 5.98$ & 5.33 & 0.002 \\
\hline & $40-49^{b}$ & $44(31.9)$ & $56.98 \pm 5.59$ & & $\mathrm{a}<\mathrm{b}, \mathrm{c}, \mathrm{d}^{*}$ \\
\hline & $50-59^{c}$ & $57(41.3)$ & $56.40 \pm 6.31$ & & \\
\hline & $\geq 60^{\mathrm{d}}$ & $12(8.7)$ & $59.75 \pm 4.58$ & & \\
\hline \multirow{4}{*}{$\begin{array}{c}\text { Clinical career } \\
\text { (years) }\end{array}$} & $<1^{\mathrm{a}}$ & $12(8.7)$ & $57.00 \pm 4.67$ & 3.98 & 0.014 \\
\hline & $1-9^{b}$ & $59(42.8)$ & $54.42 \pm 5.20$ & & $\mathrm{~b}<\mathrm{d}^{*}$ \\
\hline & $10-19^{c}$ & $46(33.3)$ & $56.83 \pm 7.31$ & & \\
\hline & $\geq 20^{\mathrm{d}}$ & $21(15.2)$ & $58.95 \pm 5.63$ & & \\
\hline \multirow{4}{*}{$\begin{array}{l}\text { Long-term care } \\
\text { hospital work } \\
\text { experience }\end{array}$} & $<1$ & $23(16.7)$ & $55.04 \pm 5.94$ & 2.40 & 0.071 \\
\hline & $1-4$ & $47(34.0)$ & $55.00 \pm 6.45$ & & \\
\hline & $5-9$ & $49(35.5)$ & $56.59 \pm 5.73$ & & \\
\hline & $\geq 10$ & $19(13.8)$ & $59.11 \pm 6.18$ & & \\
\hline \multirow{3}{*}{ Education level } & College & $100(72.5)$ & $56.68 \pm 6.12$ & 0.61 & 0.611 \\
\hline & University & $33(23.9)$ & $55.52 \pm 6.32$ & & \\
\hline & Above Graduate course & $5(3.6)$ & $58.00 \pm 4.85$ & & \\
\hline
\end{tabular}

${ }^{*}$ Post hoc test $=$ Scheffé test.

\subsection{Fall Prevention Activities by the Characteristics of the Fall}

In the fall prevention activity, the fall prevention activity was significantly higher in the subjects who cared for fall patients than never did those patients $(t=2.15$, $\mathrm{p}=0.033)$. The participants who had completed a fall prevention education were statistically significantly higher than those that did not $(t=3.32, p=0.001)$ (Table 2).

\subsection{Knowledge, Attitude and Prevention Activities of the Fall}

The total score of the subject's knowledge of falls was on average $11.70 \pm 2.18$ points out of 14 , and the percentile conversion score was 83.6 points. The attitude score for falls was averagely $49.18 \pm 4.82$ points out of 65 , and the percentile conversion score was 75.6 points. The fall prevention activity score averaged $56.14 \pm 6.17$ out of 65 , and the percentile conversion score was 86.4 (Table 3 ).

\subsection{Correlation among Falls Knowledge, Attitude and Prevention Activities of the Fall}

As a result of analyzing the correlation between the knowledge and attitudes for falls and fall prevention activities, knowledge and attitudes about falls $(r=0.45$, $\mathrm{p}<0.001)$, knowledge and fall prevention activities $(\mathrm{r}=0.27, \mathrm{p}<0.002)$ and fall attitude and preventive activities $(\mathrm{r}=0.42, \mathrm{p}<0.001)$ showed statistically significant positive correlation (Table 4). 
Table 2. Fall prevention activities by the characteristics of the fall $(\mathrm{N}=138)$.

\begin{tabular}{|c|c|c|c|c|c|}
\hline \multirow{2}{*}{ Characteristics } & \multirow{2}{*}{ Categories } & \multirow{2}{*}{$\mathrm{N}(\%)$} & Prevention activity & \multirow{2}{*}{$t / F$} & \multirow[b]{2}{*}{$\mathrm{p}$} \\
\hline & & & $\mathrm{M} \pm \mathrm{SD}$ & & \\
\hline \multirow{2}{*}{$\begin{array}{l}\text { Fall patient } \\
\text { experience }\end{array}$} & Yes & $88(63.8)$ & $56.98 \pm 6.09$ & \multirow[t]{2}{*}{2.15} & \multirow[t]{2}{*}{0.033} \\
\hline & No & $50(36.2)$ & $54.66 \pm 6.10$ & & \\
\hline \multirow{3}{*}{$\begin{array}{l}\text { The number } \\
\text { of falls experience }\end{array}$} & 1 & $25(28.4)$ & $57.60 \pm 6.88$ & \multirow[t]{3}{*}{0.86} & \multirow[t]{3}{*}{0.425} \\
\hline & 2 & $29(33.0)$ & $55.76 \pm 6.20$ & & \\
\hline & $>3$ & $34(38.6)$ & $57.56 \pm 5.36$ & & \\
\hline \multirow{2}{*}{$\begin{array}{l}\text { Fall prevention } \\
\text { training }\end{array}$} & Yes & $118(85.5)$ & $56.83 \pm 6.00$ & \multirow[t]{2}{*}{3.32} & \multirow[t]{2}{*}{0.001} \\
\hline & No & $20(14.5)$ & $52.05 \pm 5.66$ & & \\
\hline \multirow{5}{*}{$\begin{array}{l}\text { Fall prevention } \\
\text { training types }\end{array}$} & Refresher training & $30(14.5)$ & $57.06 \pm 6.29$ & \multirow[t]{5}{*}{1.76} & \multirow[t]{5}{*}{0.141} \\
\hline & On-site training & $77(53.1)$ & $56.02 \pm 5.70$ & & \\
\hline & Academic society & $5(3.5)$ & $53.40 \pm 7.89$ & & \\
\hline & Internet lecture & $25(17.2)$ & $57.75 \pm 7.20$ & & \\
\hline & Others & $8(5.5)$ & $59.56 \pm 4.40$ & & \\
\hline \multirow{3}{*}{$\begin{array}{l}\text { Fall prevention } \\
\text { training hours }\end{array}$} & $1-2$ & $52(44.1)$ & $56.12 \pm 5.39$ & \multirow[t]{3}{*}{0.76} & \multirow[t]{3}{*}{0.472} \\
\hline & $3-4$ & $35(29.6)$ & $57.49 \pm 5.38$ & & \\
\hline & $>5$ & $31(26.3)$ & $57.29 \pm 7.54$ & & \\
\hline \multirow{3}{*}{$\begin{array}{l}\text { The number of } \\
\text { fall prevention } \\
\text { training }\end{array}$} & 1 & $45(38.1)$ & $56.31 \pm 6.15$ & \multirow[t]{3}{*}{0.40} & \multirow[t]{3}{*}{0.672} \\
\hline & 2 & $39(33.1)$ & $57.49 \pm 5.75$ & & \\
\hline & $>3$ & $34(28.8)$ & $56.76 \pm 6.20$ & & \\
\hline
\end{tabular}

Table 3. Participants' knowledge, attitude, and prevention activities of the fall $(\mathrm{N}=138)$.

\begin{tabular}{cccc}
\hline Variable & Items & $\mathrm{M} \pm \mathrm{SD}$ & Min-Max \\
\hline Knowledge & 14 & $11.70 \pm 2.18$ & $0-14$ \\
Attitude & 13 & $49.18 \pm 4.82$ & $13-65$ \\
Prevention Activity & 13 & $56.14 \pm 6.17$ & $13-65$ \\
\hline
\end{tabular}

Table 4. Correlation among knowledge, attitude and prevention activities of the fall $(\mathrm{N}=$ 138).

\begin{tabular}{cccc}
\hline & Knowledge & Attitude & Prevention activity \\
\cline { 2 - 4 } Variable & $\mathrm{r}(\mathrm{p})$ & $\mathrm{r}(\mathrm{p})$ & $\mathrm{r}(\mathrm{p})$ \\
\hline Knowledge & 1 & & \\
Attitude & $0.45(<0.001)$ & 1 & 1 \\
Prevention activity & $0.27(0.002)$ & $0.42(<0.001)$ & 1 \\
\hline
\end{tabular}

\subsection{Impact of Knowledge, Attitude on Prevention Activities of the Fall}

Hierarchical multiple regression analysis, an analysis method to control the se- 
quence of input of a series of independent variables, was conducted to identify the relative strength of the effects of the impact of fall knowledge and attitudes on fall prevention activities. In this study, two-level hierarchical regression analysis was performed. In the hierarchical regression analysis Model 1, the age, clinical work experience, occupation, presence of fall experience and completion of fall prevention education were converted into dummy variables, which were statistically significant differences in the analysis of the fall prevention activities according to the general characteristics and fall-related characteristics of the subjects. In Model 2, knowledge and attitudes about falls were also converted and infused for the analysis. Durbin-Watson index was 2.02, and there was no residual autocorrelation. VIF index was $1.13-1.71$, which was less than 10, in other words, there was no problem of multicollinearity between independent variables. Next, the verification results to meet residual assumptions were satisfied for the assumptions of linearity, normality of error term, and homoscedasticity. As a result of analysis, the regression model formed in Model 1 was statistically significant, and the impact of these variables on fall prevention activities was $17 \%$. The variables that significantly influenced the fall prevention activities were the types of occupation $(\beta=-0.24, \mathrm{p}=0.012)$, and age $(\beta=0.23, \mathrm{p}=0.007)$, fall prevention activity education completion $(\beta=-0.21, \mathrm{p}=0.013)$. In Model 2 , the regression model with knowledge and attitude as independent variables was also statistically significant. The attitude toward falls $(\beta=0.32, \mathrm{p}<0.001)$ was found to have a significant effect on fall prevention activities. The influence of the variables further explained by Model 2 was 27\% and increased 10\% (Table 5).

Table 5. Effects of fall knowledge and attitude on fall prevention activities $(\mathrm{N}=138)$.

\begin{tabular}{|c|c|c|c|c|c|c|c|c|c|c|}
\hline \multirow{2}{*}{ variable } & \multicolumn{5}{|c|}{ Model 1} & \multicolumn{5}{|c|}{ Model 2} \\
\hline & B & SE & $\beta$ & $\mathrm{t}$ & $\mathrm{p}$ & $\mathrm{B}$ & SE & $\beta$ & $\mathrm{t}$ & $\mathrm{p}$ \\
\hline Constant & 54.74 & 1.52 & & 36.11 & $<0.001$ & 32.69 & 5.20 & & 6.29 & $<0.001$ \\
\hline $\operatorname{Age}^{1)}$ & 3.75 & 1.37 & 0.23 & 2.73 & 0.007 & 3.73 & 1.29 & 0.23 & 2.89 & 0.005 \\
\hline $\begin{array}{c}\text { Clinical } \\
\text { experience }^{2)}\end{array}$ & 0.82 & 1.15 & 0.07 & 0.71 & 0.480 & 0.46 & 1.09 & 0.04 & 0.42 & 0.672 \\
\hline $\begin{array}{c}\text { Have a fall } \\
\text { patient } \\
\text { experience }^{3)}\end{array}$ & -0.56 & 1.05 & -0.04 & -0.53 & 0.594 & -0.26 & 0.99 & -0.02 & -0.26 & 0.796 \\
\hline $\begin{array}{l}\text { Completion of } \\
\text { fall prevention } \\
\text { training }\end{array}$ & -3.73 & 1.48 & -0.21 & -2.52 & 0.013 & -3.09 & 1.40 & -0.18 & -2.21 & 0.029 \\
\hline Knowledge & & & & & & 0.10 & 0.25 & 0.03 & 0.39 & 0.695 \\
\hline Attitude & & & & & & 0.42 & 0.11 & 0.32 & 3.95 & $<0.001$ \\
\hline$F(p)$ & \multicolumn{5}{|c|}{$6.82(<0.001)$} & \multicolumn{5}{|c|}{$8.37(<0.001)$} \\
\hline $\mathrm{R}^{2}$ & \multicolumn{5}{|c|}{0.21} & \multicolumn{5}{|c|}{0.31} \\
\hline Adjusted $\mathrm{R}^{2}$ & \multicolumn{5}{|c|}{0.17} & \multicolumn{5}{|c|}{0.27} \\
\hline
\end{tabular}

Dummy variables' references: 1$)<40$ years old $=0,2)<10$ years $=0,3)$ Yes $=0,4)$ Yes $=0$. 


\section{Discussion}

The purpose of this study is to identify the effects of fall knowledge, attitudes, and preventive activities, and the impact of fall knowledge and attitudes on fall prevention activities.

The items that showed significant differences in fall prevention activities according to the general characteristics of the study subjects were age, work experience, and the type of industry. In the difference according to the fall-related characteristics, there was a significant difference according to whether there was a fall patient's accident experience and whether to take fall prevention education. The subjects aged 40 years old and above, with more than 20 years of clinical work experiences, and of nurses in the occupation types were found to do a lot of fall prevention activities. In the characteristics related to the fall, the fall prevention activity was significantly higher in those who had experienced a fall patient accident than in those who did not. Also, the participants completing fall prevention education were statistically significantly involved in the fall prevention activity higher than those in the opposite. A study by Kim [15] in long-term care hospital nurses also showed significant differences in fall prevention activities depending on age, clinical experience, and whether to complete fall prevention education. In a study by Oh [20], targeting nursing-related workers in elderly nursing homes, nursing-related workers with experience in falling prevention education showed a high degree of fall prevention activity, which was similar to this study. This is considered to be the result of accumulated experiences of falling directly or indirectly during the working period as the age of the subjects increased. It is interpreted that depending on the type of industry, the nurses' care and preventive activities are higher as nurses are more responsible for ward management and falls than nurses and caregivers. When the assigned patient has fallen, the participant's interest and attitude toward the fall may change, and it is thought that the fall prevention activity will become more and more reinforced. In addition, when the fall prevention education was received, it was shown that the fall prevention activity was performed effectively, suggesting that education on fall is necessary. Nursing care workers in long-term care hospitals should endeavor to acquire information in various ways and share information between long-term care hospitals in order to promote fall prevention activities, and at the hospital level, it is also necessary to seek various strategies to promote fall prevention activities. In this study, the knowledge score of falls in nursing-related workers averaged 11.7 points out of 14, and the percentile conversion score was 83.6 points. According to the study conducted in the long-term care hospital nurses using the same tool, the knowledge score of falls was similar to the knowledge score of the study subject with 81.3 points as the percentile conversion score [15]. On the other hand, compared to the Oh's study [20] conducted on nursing-related workers in elderly nursing homes, the score of this study was relatively high, as expressed as a percentile conversion score of 61.0 in the former study. The subjects who received education on fall were $59.8 \%$ in the 
Oh's study [20], and $85.5 \%$ and $77.2 \%$ in this study and Kim's study [15], respectively. It is considered relevant to the fact that there were more subjects who were trained for falls. In this study and Kim's study [15] of long-term care hospitals, the increased number of subjects with fall prevention training may attribute to the mandatory fall prevention training at the hospital level for the hospital accreditation in the elderly long-term care hospitals. However, considering that the main targets of long-term care hospitals are elderly people who are vulnerable to falls, it is required to further increase the level of fall prevention activities. As a result of analyzing the correlation between knowledge, attitudes, and preventive activities for falls, there was a strong positive correlation with knowledge and attitudes about fall of the study subjects, and a weak correlation with knowledge and preventive activities.

There was a strong positive association between attitude toward falls and prevention activities. In general, it was consistent with the findings of Seo [18] of university hospital nurses who reported that there was a net relationship between fall knowledge, attitudes, and preventive activities. However, some researches for nurses from university hospitals, long-term care hospital, and elderly nursing facilities identified that there was no significant correlation between fall knowledge and preventive activities [17] [20]. In this way, the attitude of the subject to fall was consistently reported to be correlated with the fall prevention activity, whereas the relationship between the knowledge of fall and the fall prevention activity were reported to be contrary to each other. It is considered that repeated studies should be conducted to analyze the relationship between them. In this study, a two-level hierarchical regression analysis was conducted to identify factors affecting the fall prevention activities of nursing care workers in long-term care hospitals. In the first stage, the type of occupation, age, and completion of fall prevention education significantly influenced. In the second stage, where knowledge and attitudes about fall were applied, the higher the attitude toward falling, the more the fall prevention activities were found. This is a study to identify the factors influencing fall prevention activities, although there are limitations compared to some previous studies. In a study by Jin [23], which used hierarchical regression analysis to influence the fall prevention activities of nurses in general hospitals, the research showed the same results with this study that the experience of fall prevention education affected in step 1and the attitude toward falls had a significant effect in step 2. A study by Jung and Jeong [21], targeting nurses in long-term care hospitals, presented that the fall prevention activities were affected in the order of fall attitude, fall prevention education time, and salary. Another study that conducted on nurses in other long-term care hospitals, also showed that the attitude toward falls, the age, and the fall prevention education had an effect on fall prevention activities [15]. This results in that the attitude toward fall had the most influence on the fall prevention activity as this research identified. However, it was found that knowledge of falls did not significantly affect fall prevention activities. Koh et al. [24] reported the barriers of the "fall prevention guidelines" to nurses at Singa- 
pore hospitals as related to lack of knowledge. Consequently, the knowledge of fall prevention was raised through educational intervention, and yet fall prevention was not effectively implemented [24].

This report points out that it is more necessary to change their attitude rather than to improve knowledge and competency to prevent falls [25], which supports the importance of the attitude toward falling. From these results, it can be seen that the attitude toward fall is the most important factor in determining fall prevention activities. Therefore, in order to promote the fall prevention activities of nursing care workers in long-term care hospitals, it is crucial to first cultivate an interest in fall prevention and an attitude to participate in fall prevention activities. Next, the older the age was, the more influence the subjects had on fall prevention activities. This is considered to be the result of accumulated experiences of falling directly or indirectly during the working period as the age increases. In addition, the completion of fall prevention education was one of the factors affecting the fall prevention activities. In the previous studies, the subjects who received fall prevention education were reported to implement a high degree of fall prevention activity [11] [18] [23]. In view of these results, it is critical to conduct differentiated fall prevention education tailored to the characteristics of nursing workers, and it is regarded that various strategies for effective fall prevention methods should be developed. This study identified the effects of fall knowledge and attitudes on fall prevention activities, and examined the relationship between attitudes about fall, general characteristics, and fall related characteristics of nursing care workers in long-term care hospitals. The result of this research is meaningful in terms of the supply of basic information to prevent fall in the future. Based on this, it can be effectively utilized to develop strategies that can change the attitude of nursing workers to falls. However, this study was limited to generalizing the results of the study because only 5 long-term care hospitals in 2 regions were sampled.

\section{Conclusion}

This study aimed to devise a more effective strategy to prevent falls in the elderly by grasping the effects of falls knowledge and attitudes on fall prevention activities for nursing care workers in long-term care hospitals. As a result of the study, the knowledge of falls in nursing care workers in those hospitals was high, and the attitude toward falling and prevention of falls were moderate. There was a positive correlation between the fall knowledge and attitude and fall prevention activities. The attitude toward fall was also a factor influencing the fall prevention activities. The results of this study verified that the attitude of nursing care workers to fall should be established in order to promote the fall prevention activities of long-term care hospitals. Therefore, effective and diverse strategies also should be developed to induce the change of attitudes toward fall and preventive activities for nursing-related workers. Based on the above research results, the researchers suggest the development and provision of various educational programs that can actively change the attitude toward falling in order to promote 
fall prevention activities. In addition, it suggests a study to verify the effectiveness of differentiated fall prevention education corresponding to the characteristics of nursing workers.

\section{Author's Contributions}

Conceptualization: Han YH, Kim, HY.

Data collection, analysis and writing original draft: Han YH, Hong HS.

Writing-review and editing: Kim HY, Hong HS.

\section{Conflicts of Interest}

The authors declare no conflicts of interest regarding the publication of this paper.

\section{References}

[1] Korean Statistical Information Service (2016) Population and Aging Index Trends by Age Group.

http://kosis.kr/conts/nsportalStats/nsportalStats_0102Body.jsp?menuId=10\&NUM $=1014$

[2] Kim, D.W., Nam, M.A., Roh, B.I., Shin, C.S., Sim, W.C., et al. (2010) Modern Social Issues and Social Welfare. Hakjisa, Seoul.

[3] National Health Insurance Service (2017) Status of Medical Care Institutions by Province. http://www.nhis.or.kr/menu/retriveMenuSet.xx?menuId=F4633

[4] Buckinx, F., Croisier, J.-L., Reginster, J.-Y., Lenaerts, C., Brunois, T., Rygaert, X., et al. (2018) Prediction of the Incidence of Falls and Deaths among Elderly Nursing Home Residents: The SENIOR Study. Journal of the American Medical Directors Association, 19, 18-24. https://doi.org/10.1016/j.jamda.2017.06.014

[5] Kim, M. and Kim, J.S. (2013) Effects of the Fall Prevention Education Program (FPEP) for Caregivers in Elderly Care Facilities on Fall-Related Knowledge, Fall-Related Burden, and Caring Behaviors for Fall Prevention. Journal of the Korea Contents Association, 13, 778-790. https://doi.org/10.5392/JKCA.2013.13.11.778

[6] Zurmehly, J (2018) Implementing a Nurse-Driven Protocol to Reduce Catheter-Associated Urinary Tract Infections in a Long-Term Acute Care Hospital. The Journal of Continuing Education in Nursing, 49, 372-377. https://doi.org/10.3928/00220124-20180718-08

[7] Kim, D. and Lee, H.J. (2014) Effects on Long-Term Care Hospital Staff Mixing Level after Implementing Differentiated Inpatient Nursing Fees by Staffing Grades. Journal of Korean Academy of Nursing Administration, 20, 95-105. https://doi.org/10.5392/JKCA.2013.13.11.778

[8] Spoelstra, S.L., Given, B.A. and Given, C.W. (2012) Fall Prevention in Hospitals: An Integrative Review. Clinical Nursing Research, 21, 92-112. https://doi.org/10.1177/1054773811418106

[9] Graham, B.C. (2012) Examining Evidence-Based Interventions to Prevent Inpatient Falls. Medsurg Nursing, 21, 267-270.

[10] Callis, N. (2016) Falls Prevention: Identification of Predictive Fall Risk Factors. Applied Nursing Research, 29, 53-58. https://doi.org/10.1016/j.apnr.2015.05.007

[11] Kim, S.H. and Seo, J.M. (2017) Geriatric Hospital Nurses' Knowledge, Attitude to- 
ward Falls, and Fall Prevention Activities. Journal of Korean Gerontological Nursing, 19, 81-91. https://doi.org/10.17079/jkgn.2017.19.2.81

[12] Spiva, L.A., Robertson, B., Delk, M., Patrick, S., Kimrey, M., Green, B. and Gallagher, E. (2014) Effectiveness of Team Training on Fall Prevention. Journal of Nursing Care Quality, 29, 164-173. https://doi.org/10.1097/NCQ.0b013e3182a98247

[13] Agency for Healthcare Research and Quality (2011) Surveys on Patient Safety Culture. http://www.ahrq.gov/qual/patientsafetyculture/

[14] Rogers, E.M. (2003) Diffusion of Innovations. 5th Edition, Free Press, New York.

[15] Kim, S.H. (2013) Fall, Knowledge, Attitude and Fall Prevention Activities of Nurses in Elderly Hospitals. Master Thesis, Busan University, Busan.

[16] Kim, S.A. and Jeon, H.W. (2011) A Study on the Elderly Care Facilities Worker's Attitude and Awareness of Associated Factors of Falls. The Journal of Vocational Educational Research, 30, 89-111.

[17] Leone, R.M. and Adams, R.J. (2016) Safety Standards: Implementing Fall Prevention Interventions and Sustaining Lower Fall Rates by Promoting the Culture of Safety on an Inpatient Rehabilitation Unit. Rehabilitation Nursing, 41, 26-32. https://doi.org/10.1002/rnj.250

[18] Seo, O.I. (2008) Effects of Knowledge and Attitudes about Fall Inpatients of Some University Hospital Nurses on Fall Prevention Behavior. Master Thesis, The Catholic University of Korea, Seoul.

[19] Lee, H.J. (2016) Factors Related to Attitude and Prevention Activity for Patient's Fall among General Hospital's Nurse. Master Thesis, Inje University, Gimhae.

[20] Oh, H.S. (2014) A Study on the Knowledge, Attitude, and Prevention Activities of Falls in Nursing Care Workers for the Elderly. Master Thesis, Nambu University, Gwangju.

[21] Jung, J.Y. and Jung, G.H. (2016) The Affect Factors of Geriatric Hospital Nurse's Falls Prevention Activities. Journal of Health Informatics and Statistics, 41, 203-211. https://doi.org/10.21032/jhis.2016.41.2.203

[22] Lee, I.K. and Choi, J.Y. (2013) Factors Associated with Nurses' Activities for Hospital Fall Prevention. The Korean Journal of Rehabilitation Nursing, 16, 55-62. https://doi.org/10.7587/kjrehn.2013.55

[23] Jin, M.S. (2016) Factors Affecting Nurse Fall Prevention Activities by Hospital Level. Master Thesis, Kyungsang University, Busan.

[24] Koh, S.L., Manias, E., Hutchinson, A.M., Donath, S. and Johnston, L. (2008) Nurses' Perceived Barriers to the Implementation of a Fall Prevention Clinical Practice Guideline in Singapore Hospitals. BMC Health Services Research, 8, 105-114. https://doi.org/10.1186/1472-6963-8-105

[25] Tzeng, H.-M. (2011) Nurses' Caring Attitude: Fall Prevention Program Implementation as an Example of Its Importance. Nursing Forum, 46, 137-145. https://doi.org/10.1111/j.1744-6198.2011.00222.x 


\section{Appendix 1: Questionnaire for This Study in English}

I. The following items are for your general and falls related traits. Please mark " $\sqrt{ }$ " where applicable for each question or fill in ( ) directly.

1 . What is your gender?

(1) man (2) woman

2. How old are you? Age ( )

3. What is your clinical work experience? (Year: Month: )

4. What is your work experience at the long-term hospital? (Year: Month: )

5. What is your profession? Nurse ( ) Nurse Aid ( )

6. What is your final academic background?

(1) High school graduate (2) Technical college graduate (3) University graduate

(4) Graduate school or higher (5) Other

7-1. Do you have any experience of falling accidents in your charge?

(1) Yes (2) No

7-2. If yes, how many falling experiences have you had? ( ) times

8-1. Have you had any falling prevention training in the past year?

(1) Yes (2) No

8-2. If yes, where did you get falls training?

(1) Refresher training (2) In-service training in the facility (3) Academic Society (4) Internet lecture (5) Other

8-3. How long have you been in falls training in the last year? ( ) hours

8-4. How many times did you attend falls training in the past year? () times

II. The questions below are about knowledge of fall. Please check the number that is closest to what you normally think.

\begin{tabular}{|c|c|c|c|c|}
\hline No. & Questions & Yes & No & I don't know \\
\hline 1 & $\begin{array}{l}\text { Older people who have experienced falls in the } \\
\text { past are likely to fall again. }\end{array}$ & (1) & (2) & (3) \\
\hline 2 & $\begin{array}{l}\text { Falling is the most frequent among the hospital } \\
\text { safety accidents for hospitalized elderly. }\end{array}$ & (1) & (2) & (3) \\
\hline 3 & Falling increases the mortality rate of older people. & (1) & (2) & (3) \\
\hline 4 & Most hip fractures in the elderly are caused by falls. & (1) & (2) & (3) \\
\hline $5^{\star}$ & Sliding is not a fall. & (1) & (2) & (3) \\
\hline 6 & $\begin{array}{l}\text { The more drugs you take, the greater your risk of } \\
\text { falling. }\end{array}$ & (1) & (2) & (3) \\
\hline 7 & $\begin{array}{l}\text { The greater the number of diseases, the greater } \\
\text { the risk of falling. }\end{array}$ & (1) & (2) & (3) \\
\hline $8^{*}$ & Depression and falling are not related. & (1) & (2) & (3) \\
\hline 9 & $\begin{array}{l}\text { People with vision impairments are at increased } \\
\text { risk of falling. }\end{array}$ & (1) & (2) & (3) \\
\hline $10^{*}$ & $\begin{array}{l}\text { People with insensitive hands and feet are not } \\
\text { associated with falls. }\end{array}$ & (1) & (2) & (3) \\
\hline
\end{tabular}




\section{Continued}

\begin{aligned} \hline 11 & $\begin{array}{l}\text { Urination disorders such as urination, bedwetting, } \\ \text { and incontinence are risk factors for falls. }\end{array} \\ 12^{*} \begin{array}{l}\text { There is no connection between hearing problems } \\ \text { and falls. }\end{array} &$ (1) \\ $13^{*} \quad$ Taking medications and falls are not related. & (1) \\ 14 & $\begin{array}{l}\text { In hospitals, a lot of falls occur when going up } \\ \text { and down a bed. }\end{array}\end{aligned}$

${ }^{*}$ Reverse question.

III. The questions below are about attitudes toward falling. Please check the number that is closest to what you normally think.

\begin{tabular}{|c|c|c|c|c|c|c|}
\hline No. & Question & $\begin{array}{l}\text { Strongly } \\
\text { disagree }\end{array}$ & Disagree & $\begin{array}{c}\text { Neither agree } \\
\text { or disagree }\end{array}$ & Agree & $\begin{array}{c}\text { Strongly } \\
\text { agree }\end{array}$ \\
\hline 1 & $\begin{array}{l}\text { I am interested in the fall of } \\
\text { hospitalized patients. }\end{array}$ & (1) & (2) & (3) & (4) & (5) \\
\hline $2^{*}$ & $\begin{array}{l}\text { I think that it is inevitable for a } \\
\text { hospitalized patient to fall. }\end{array}$ & (1) & (2) & (3) & (4) & (5) \\
\hline 3 & $\begin{array}{l}\text { I think that falling in the hospital is } \\
\text { an important responsibility of } \\
\text { nurse and care providers. }\end{array}$ & (1) & (2) & (3) & (4) & (5) \\
\hline 4 & $\begin{array}{l}\text { I think that the prevention of falls } \\
\text { is a high care and treatment. }\end{array}$ & (1) & (2) & (3) & (4) & (5) \\
\hline 5 & $\begin{array}{l}\text { I'm interested in activities to } \\
\text { prevent falls. }\end{array}$ & (1) & (2) & (3) & (4) & (5) \\
\hline 6 & $\begin{array}{l}\text { I think it is necessary to actively } \\
\text { care and treat patients to } \\
\text { prevent falls. }\end{array}$ & (1) & (2) & (3) & (4) & (5) \\
\hline 7 & $\begin{array}{l}\text { I believe that the risk of falls } \\
\text { associated with a patient should } \\
\text { be assessed (identified) when } \\
\text { hospitalized. }\end{array}$ & (1) & (2) & (3) & (4) & (5) \\
\hline $8^{*}$ & $\begin{array}{l}\text { I think that the current fall } \\
\text { prevention education is sufficient } \\
\text { when hospitalized. }\end{array}$ & (1) & (2) & (3) & (4) & (5) \\
\hline $9^{*}$ & $\begin{array}{l}\text { I think that falls are due to the } \\
\text { patient's condition. }\end{array}$ & (1) & (2) & (3) & (4) & (5) \\
\hline 10 & $\begin{array}{l}\text { I think that nursing staff should } \\
\text { respond immediately if they ask for } \\
\text { help when they are about to move. }\end{array}$ & (1) & (2) & (3) & (4) & (5) \\
\hline $11^{\star}$ & $\begin{array}{l}\text { I don't think that there is severe } \\
\text { physical damage if the patient falls. }\end{array}$ & (1) & (2) & (3) & (4) & (5) \\
\hline $12^{\star}$ & $\begin{array}{l}\text { I think that the hospital } \\
\text { environment is safe against falls. }\end{array}$ & (1) & (2) & (3) & (4) & (5) \\
\hline 13 & If my patient falls, I will feel guilty. & (1) & (2) & (3) & (4) & (5) \\
\hline
\end{tabular}

${ }^{*}$ Reverse question. 
IV. The questions below are about fall prevention activities. Please check the number that is closest to what you normally think.

\begin{tabular}{|c|c|c|c|c|c|c|}
\hline No. & Question & $\begin{array}{l}\text { Strongly } \\
\text { disagree }\end{array}$ & Disagree & $\begin{array}{c}\text { Neither agree } \\
\text { or disagree }\end{array}$ & Agree & $\begin{array}{c}\text { Strongly } \\
\text { agree }\end{array}$ \\
\hline 1 & $\begin{array}{l}\text { The risk factors for falling are notified } \\
\text { to patients and their caregivers who } \\
\text { are at high risk of falling. }\end{array}$ & (1) & (2) & (3) & (4) & (5) \\
\hline 2 & $\begin{array}{l}\text { When getting on and off a wheelchair, } \\
\text { make sure that the wheels are fixed } \\
\text { when climbing and lowering the bed. }\end{array}$ & (1) & (2) & (3) & (4) & (5) \\
\hline 3 & $\begin{array}{l}\text { The patients who are at high risk of } \\
\text { falling will be explained how to use } \\
\text { the wheelchairs in advance. }\end{array}$ & (1) & (2) & (3) & (4) & (5) \\
\hline 4 & $\begin{array}{l}\text { Make sure that the bed railing is } \\
\text { raised when the patients are in bed. }\end{array}$ & (1) & (2) & (3) & (4) & (5) \\
\hline 5 & $\begin{array}{l}\text { Make sure that patients at high risk } \\
\text { of falling always hold the railing when } \\
\text { going up and down a bed or staircase. }\end{array}$ & (1) & (2) & (3) & (4) & (5) \\
\hline 6 & $\begin{array}{l}\text { Explain that patients with high risk } \\
\text { of falling slowly move their bodies } \\
\text { when changing positions, and } \\
\text { help if necessary. }\end{array}$ & (1) & (2) & (3) & (4) & (5) \\
\hline 7 & $\begin{array}{l}\text { When patients are tired or dizzy, } \\
\text { always educate them to ask for help. }\end{array}$ & (1) & (2) & (3) & (4) & (5) \\
\hline 8 & $\begin{array}{l}\text { Encourage the patient not to run } \\
\text { around in the patient's room or } \\
\text { hallway or not to walk quickly with } \\
\text { unstable steps. }\end{array}$ & (1) & (2) & (3) & (4) & (5) \\
\hline 9 & $\begin{array}{l}\text { Instruct the patient with the high } \\
\text { risk of falls where call lights of } \\
\text { patient's room and restroom are } \\
\text { placed, and how to use the call lights. }\end{array}$ & (1) & (2) & (3) & (4) & (5) \\
\hline 10 & $\begin{array}{l}\text { Check for slippery floors in hallways, } \\
\text { patient's rooms, treatment rooms, } \\
\text { and restrooms. }\end{array}$ & (1) & (2) & (3) & (4) & (5) \\
\hline 11 & $\begin{array}{l}\text { Make sure that patient at high risk } \\
\text { of falling wears shoes that don't } \\
\text { slip and fit well. }\end{array}$ & (1) & (2) & (3) & (4) & (5) \\
\hline 12 & $\begin{array}{l}\text { Make sure that the lighting in the } \\
\text { hallway, patient's room, treatment } \\
\text { room, and restroom is bright enough. }\end{array}$ & (1) & (2) & (3) & (4) & (5) \\
\hline 13 & $\begin{array}{l}\text { Make sure that patient is wearing a } \\
\text { seat belt when using a wheelchair. }\end{array}$ & (1) & (2) & (3) & (4) & (5) \\
\hline
\end{tabular}

